\title{
Risk factors for complications of pancreatic extracorporeal shock wave lithotripsy
}

Authors

Institutions

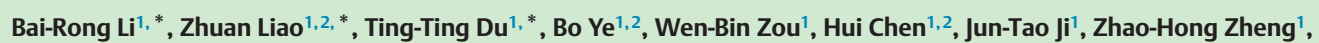
Jun-Feng Hao ${ }^{1}$, Ying-Yi Jiang ${ }^{1,2}$, Liang-Hao Hu ${ }^{1,2}$, Zhao-Shen $\mathrm{Li}^{1,2}$

${ }^{1}$ Department of Gastroenterology, Changhai Hospital, Second Military Medical University, Shanghai, China

${ }^{2}$ Digestive Endoscopy Center, Changhai Hospital, Second Military Medical University, Shanghai, China submitted: 18. March 2014 accepted after revision: 2. July 2014

\section{Bibliography}

Dol http://dx.doi.org/

10.1055/s-0034-1377753

Published online: 24.9 .2014

Endoscopy 2014; 46: 10921100

(c) Georg Thieme Verlag KG Stuttgart · New York ISSN 0013-726X

\section{Corresponding author Liang-Hao Hu, MD} or Zhao-Shen Li, MD

Department of Gastroenterology Digestive Endoscopy Center Changhai Hospital The Second Military Medical University 168 Changhai Road Shanghai 200433

China

Fax: +86-21-55621735

lianghao-hu@hotmail.com zhaoshen-li@hotmail.com
Background and study aims: Extracorporeal shock wave lithotripsy is recommended as treatment for stones in chronic pancreatitis. The aim of this study was to investigate the risk factors for complications of pancreatic extracorporeal shock wave lithotripsy (P-ESWL).

Patients and methods: Patients with painful chronic pancreatitis and pancreatic stones ( $>5$ $\mathrm{mm}$ diameter) who were treated with P-ESWL between March 2011 and June 2013 were prospectively included. Adverse events after P-ESWL were classified as complications and transient adverse events, depending on severity. The major complications of P-ESWL included post-ESWL pancreatitis, bleeding, infection, steinstrasse, and perforation. Multivariate analyses based on univariate analysis were performed to detect risk factors of overall and moderate-to-severe complications.

Results: A total of 634 patients underwent 1470 P-ESWL procedures. The overall complication rate was $6.7 \%$ of all procedures. Complications oc-

\section{Introduction}

$\nabla$

Intracanalar or intraductal stones are pathognomonic signs of chronic pancreatitis and occur in approximately $90 \%$ of patients with this longstanding disease. These stones further obstruct the outflow from the pancreas, leading to recurrent attacks of pancreatitis and abdominal pain. Endoscopic retrograde cholangiopancreatography (ERCP), the primary method used to eliminate pancreatic stones, fails to treat more than half of the patients with chronic pancreatitis bearing pancreatic stones [1]. As such, extracorporeal shock wave lithotripsy (ESWL) has been developed to treat pancreatic stones when rou-

\section{License terms}

\section{()(1) $\ominus \circledast$}

* Drs. Li, Liao, and Du contributed equally to this study. curred in 62 patients (9.8\%) after the first ESWL procedure. The risk factors for complications were pancreas divisum (odds ratio [OR] 1.28) and the interval between diagnosis of chronic pancreatitis and P-ESWL (OR 1.28). Protective factors were male sex (OR 0.50), diabetes (OR 0.45), and steatorrhea (OR 0.43). Male sex, the only identified predictor for moderate-to-severe complications, was a protective factor (OR 0.19). For the second P-ESWL procedure, complications occurred in 22/409 patients (5.4\%). Complication and asymptomatic hyperamylasemia after the first ESWL session were significantly associated with higher risk for complications after the second ESWL session $(P<0.05)$.

Conclusions: Patient-related factors were important in determining a high risk of P-ESWL complications when no procedure-related factors were identified. Patients suffering from complications after the first ESWL session were also likely to experience complications in subsequent P-ESWL sessions.

tine endotherapy cannot be applied effectively [2].

In pancreatic ESWL (P-ESWL), impacted stones in the pancreas are fractured or loosened; stone clearing is then achieved either spontaneously or via ERCP [3, 4]. This procedure was first used to remove pancreatic stones in 1987; since then, PESWL has been safely and effectively applied [2, 5-9]. However, a few patients may suffer from adverse events caused by related stone fragments and injury to the tissues surrounding the pancreas. Given the lack of established definition and classification for the adverse events of P-ESWL, the reported prevalence varies from $0 \%$ to $20 \%$ [10]. The adverse events include skin erythema, hematuria, post-ESWL pancreatitis, bleeding, and perforation [5-7,11-16]. Several of these adverse events are mild and transient, and do not require medical intervention, whereas other con- 
Table 1 Definitions of major complications of pancreatic extracorporeal shock wave lithotripsy.

\begin{tabular}{|c|c|c|c|}
\hline Complications $^{1}$ & Mild & Moderate & Severe \\
\hline $\begin{array}{l}\text { Post-ESWL } \\
\text { pancreatitis }\end{array}$ & $\begin{array}{l}\text { Clinical pancreatitis, amylase at least } \\
\text { three times the normal level at }>24 \text { hours } \\
\text { after procedure, requires admission or } \\
\text { extension of planned admission from } \\
2 \text { days to } 3 \text { days }\end{array}$ & Requires hospitalization of $4-10$ days & $\begin{array}{l}\text { Hospitalization for }>10 \text { days, pseudocyst, } \\
\text { or intervention (percutaneous drainage } \\
\text { or surgery) }\end{array}$ \\
\hline Bleeding $^{2}$ & $\begin{array}{l}\text { Clinical evidence of bleeding, } \\
\text { hemoglobin drop < } 3 \mathrm{~g} \text {, no transfusion }\end{array}$ & $\begin{array}{l}\text { Transfusion of } \leq 4 \text { units, no angiographic } \\
\text { intervention, or surgery }\end{array}$ & $\begin{array}{l}\text { Transfusion of } \geq 5 \text { units or intervention } \\
\text { (angiographic or surgical) }\end{array}$ \\
\hline Infection & $>38^{\circ} \mathrm{C}$ for $24-48$ hours & Requires $>3$ days of hospital treatment & $\begin{array}{l}\text { Abscess, septic shock, or intervention } \\
\text { (percutaneous drainage or surgery) }\end{array}$ \\
\hline Steinstrasse ${ }^{3}$ & $\begin{array}{l}\text { Severe abdominal pain without other } \\
\text { post-ESWL complications }\end{array}$ & $\begin{array}{l}\text { Combined with other complications, or } \\
\text { requires }>3 \text { days of hospital treatment }\end{array}$ & $\begin{array}{l}\text { Combined with other complications; } \\
\text { hospitalization for }>10 \text { days, or surgery }\end{array}$ \\
\hline Perforation & $\begin{array}{l}\text { Possible, or very slight leak of fluid, } \\
\text { treatable with fluids and suction for } \\
\leq 3 \text { days }\end{array}$ & $\begin{array}{l}\text { Any definite perforation treated } \\
\text { medically for } 4-10 \text { days }\end{array}$ & $\begin{array}{l}\text { Medical treatment for }>10 \text { days or } \\
\text { intervention (percutaneous or surgical) }\end{array}$ \\
\hline
\end{tabular}

ESWL, extracorporeal shock wave lithotripsy.

${ }^{1}$ Splenic rupture, pancreaticobiliary fistula, and other rare complications were not included in this classification of complications.

2 Acute gastrointestinal mucosal injury was not included, but was classified as a transient adverse event.

${ }^{3}$ Steinstrasse [18]: acute stone incarceration in the papilla leading to poor pancreatic juice drainage. Computed tomography shows a more dilated pancreatic duct with/without acute pancreatitis. Severe abdominal pain that cannot be relieved by analgesics could be relieved by emergency endoscopic retrograde cholangiopancreatography or ESWL.

ditions need specific medical treatment or prolonged hospitalization and may even be considered as life threatening $[14,16]$. Therefore, adverse events should be classified and risk factors should be identified to improve the safety of P-ESWL.

The aim of this prospective study was to identify the risk factors associated with the development of adverse events in P-ESWL.

\section{Patients and methods}

\section{$\nabla$}

This prospective observational study was performed at a tertiary referral center. All patients with chronic pancreatitis who were treated with P-ESWL for pancreatic stones between March 2011 and June 2013 at Changhai Hospital were included. Written informed consent was obtained from each patient. The study was approved by the Ethics Committee of Changhai Hospital.

\section{Patients}

The diagnosis of chronic pancreatitis was established according to the Asia-Pacific consensus [17]. P-ESWL was performed in patients suffering from painful chronic pancreatitis with at least one large pancreatic stone $(>5 \mathrm{~mm}$ in diameter). Patients with previous ERCP or pancreatic surgery for chronic pancreatitis were also considered for inclusion in the study. Patients with isolated pancreatic tail stone, suspected or established malignancy, pancreatic ascites, and pregnancy were excluded. Patients with cholangitis, resulting from common bile duct (CBD) strictures secondary to chronic pancreatitis, were treated with PESWL after cholangitis had subsided.

\section{Classification of adverse events}

An adverse event of P-ESWL is an undesired harmful event, and was classified as either a complication or a transient adverse event (TAE), depending on severity. To date, no firm definition of a severe adverse event or complication of P-ESWL has been established. In the current study, complications were recognized as adverse events needing specific medical intervention and prolonged hospitalization. Based on published studies [5-7,11-16] and our clinical experience [18], major complications were classified into five groups (post-ESWL pancreatitis, bleeding, infection, steinstrasse, and perforation). Steinstrasse was defined as acute stone incarceration in the papilla that leads to poor pancreatic juice drainage, and computed tomography (CT) findings of dilated pancreatic duct with/without acute pancreatitis [18]. Severe abdominal pain caused by steinstrasse that cannot be relieved by analgesics should be relieved by emergency ERCP or ESWL. In reference to the ERCP complication classification [19], P-ESWL complications were also stratified as mild, moderate, or severe depending mainly on the length of hospitalization and the need for invasive treatment ( Table 1). Splenic rupture, pancreaticobiliary fistula, and other rare complications were not included in this classification. In addition to complications, TAEs referring to mild adverse events were proposed. TAEs were defined as transient injuries caused by shock waves, which required no medical intervention and did not prolong hospitalization. TAEs included skin erythema, mild tenderness of the region in contact with the shockwave head, asymptomatic hyperamylasemia, hematuria, and acute gastrointestinal mucosal injury (manifested as hematemesis and melena). Asymptomatic hyperamylasemia was defined as an increase in serum amylase compared with pre-ESWL levels and beyond the upper limit of the normal range but showing no related symptoms.

\section{P-ESWL procedure}

P-ESWL was performed by two gastroenterologists (L. H. H. and B. Y) using an electromagnetic lithotripter (Compact Delta II; Dornier Med Tech., Wessling, Germany) with bi-dimensional fluoroscopic targeting facility. The pretreatment procedure was similar to that for ERCP. Intravenous remifentanil combined with flurbiprofen was administered for analgesia during the procedure. Before P-ESWL was started, $50 \mathrm{mg}$ flurbiprofen was intravenously infused, and continuous remifentanil infusion (initial concentration $12 \mu \mathrm{g} / \mathrm{h} \cdot \mathrm{kg}$ ) was started. The concentration of remifentanil was slightly adjusted according patient assessment of pain (on a visual analog scale) and breathing rate. During the procedure, another $50 \mathrm{mg}$ flurbiprofen was administered if the patient complained of gradually intensifying pain.

Patients were placed in the supine position or were tilted to their right side at an angle of $30^{\circ}\left(\bullet\right.$ Fig. 1 ). The $30^{\circ}$-right supine position may facilitate effective contact with the shockwave head and avoid the vertebrae and stones from overlapping in the image. Stones were directly targeted fluoroscopically in patients with 


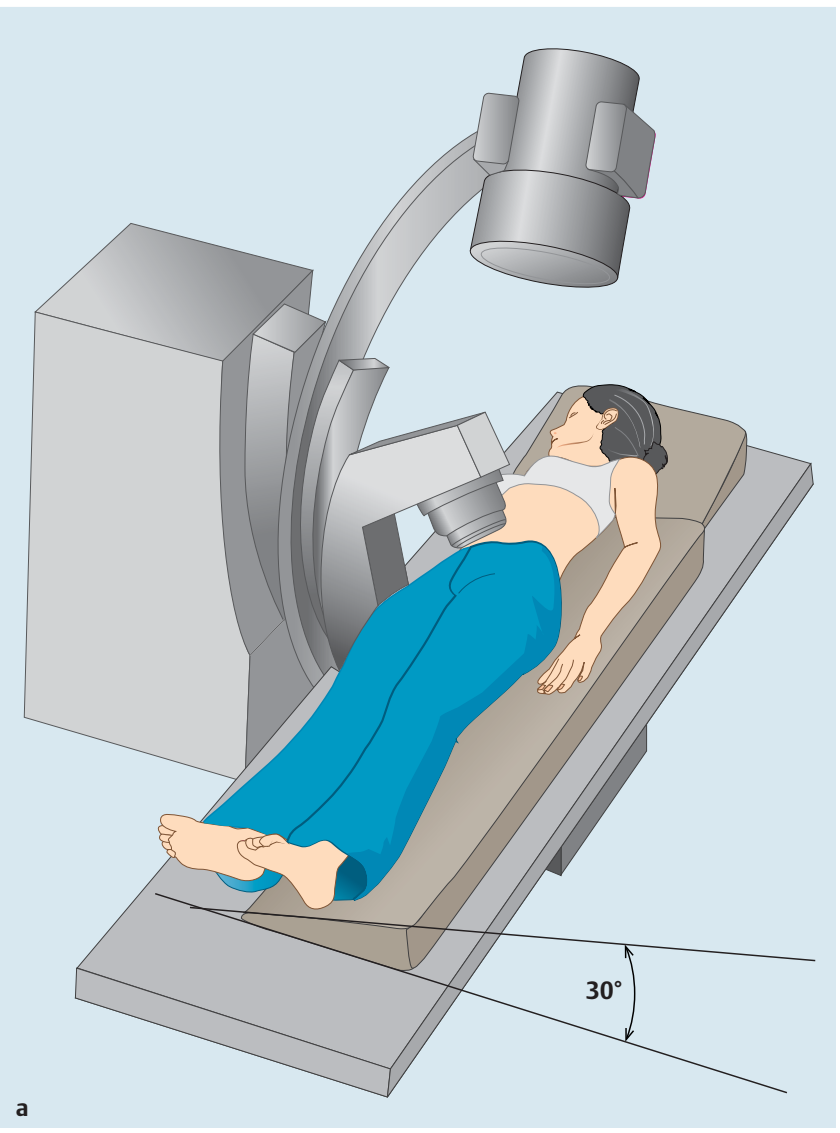

opaque stones. For patients with radiolucent stones, a nasopancreatic tube was inserted after pancreatic sphincterotomy to facilitate fluoroscopic targeting during P-ESWL. The exposure was limited to a maximum of 5000 shock waves per session. An intensity ranging from 1 to 6 was used with a frequency of 60-120 shocks per minute during the procedure. The duration of each session was 60-90 minutes. The fragmentation of the stones was monitored by fluoroscopy during the P-ESWL session.

Repeat P-ESWL sessions were performed over consecutive days until the stones had been fragmented to $3 \mathrm{~mm}$ or less in size. For patients with P-ESWL complications, the next P-ESWL session was recommended when the patient had recovered from complications. Although it was agreed that ESWL alone is a more costeffective strategy than ESWL combined with ERCP for selected patients $[3,20]$, ERCP was routinely performed in the current study after the last P-ESWL session, in order to remove stone fragments and complete the visualization of the pancreatic duct system. Pancreatic stents (5-10 Fr) were inserted for patients with dominant main pancreatic duct (MPD) stricture, MPD rupture, or pseudocyst that necessitated stent placement for drainage [20].

\section{Data collection}

The following data were prospectively recorded: demographic data (age, sex, height, and weight), course and medical history of chronic pancreatitis and other diseases, smoking and alcohol status, disease history of family members, and characteristics of pancreatic stones (number, location, and distribution). Previous treatments (endoscopic papillotomy, pancreatic stent, CBD stent, etc.) were also recorded. P-ESWL procedure-related information, including the location, number, and size of targeted stones, energy level, pressure of water capsule, shockwave frequency, num-



Fig. 1 Position of patient for extracorporeal shock wave lithotripsy. a The patient was tilted to the right side at an angle of $30^{\circ}\left(30^{\circ}\right.$-right supine position; illustrated by Ji JT). b When lying in a supine position, the stones in the head and body of the pancreas overlap with the spine in the image. $\mathrm{c} \mathrm{In}$ the $30^{\circ}$-right supine position, there is no overlapping of structures and a better vision of the

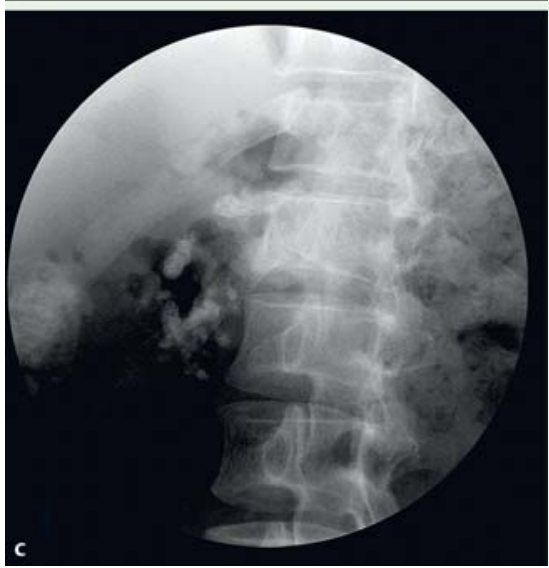
stones is obtained.

ber of shock waves, and the number of P-ESWL sessions, was collected in detail. The characteristics of the MPD were evaluated based on CT, magnetic resonance imaging, endoscopic ultrasound, and/or previous ERCP (post-P-ESWL ERCP when needed). The complications and TAEs of P-ESWL were recorded in detail. Delayed complications were also collected during the 1-month follow-up period after discharge. The treatment for each complication was recorded. Skin erythema and mild tenderness from contact with the shockwave head were not analyzed because these adverse events were observed in almost all of the patients.

\section{Data analysis}

For patients undergoing more than one P-ESWL session, only the first procedure was included in the analysis of risk factors. The potential risk factors of P-ESWL adverse events are listed in detail in Table 2. Continuous variables were assessed using $t$ test or nonparametric Mann-Whitney $U$ test as indicated in the univariate analysis. Continuous variables were also transformed to categorical variates (ordinal variates when needed) based on prior studies and clinical experience. Chi-squared analysis or Fisher's exact test was used for categorical variables. A logistic regression model was used for multivariate analysis to identify the independent risk factors for P-ESWL complications, moderate or severe (moderate-to-severe) complications, post-ESWL pancreatitis, and TAEs. Odds ratios (ORs) and 95\% confidence intervals (CIs) were calculated. Statistical analyses were conducted at a significance level of 0.10 for univariate analysis and 0.05 for multivariate analysis. Data were analyzed using SPSS 18.0 (SPSS, Chicago, Illinois, USA). 
Table 2 Potential predictors of pancreatic extracorporeal shock wave lithotripsy complications involved in risk factor analysis.

\begin{tabular}{|c|c|}
\hline Categories & Potential risk factors \\
\hline General characteristics & Sex, smoking index, smoking status, alcohol consumption ${ }^{1}$, alcohol status, body mass index \\
\hline Medical history & Hypertension, hyperlipidemia, previous abdominal surgery, cholecystectomy, previous gastric surgery \\
\hline Family history & First-degree relatives with diabetes, first-degree relatives with pancreas disease ${ }^{2}$ \\
\hline $\begin{array}{l}\text { Chronic pancreatitis } \\
\text { course }\end{array}$ & $\begin{array}{l}\text { Diabetes, steatorrhea, CBD stenosis, pseudocyst, MPD stenosis, pancreas divisum, abnormal pancreaticobiliary junction, } \\
\text { HCP } \\
\text { Age at: onset of chronic pancreatitis; diagnosis of chronic pancreatitis; stone diagnosis; diabetes; steatorrhea; CBD stenosis; } \\
\text { pseudocyst } \\
\text { Initial symptom (pain/functional insufficiency/others); types of pain [21] } \\
\text { Time between: onset of chronic pancreatitis and CBD stenosis; onset of chronic pancreatitis and pseudocyst formation; onset } \\
\text { of chronic pancreatitis and first-ESWL; diagnosis of chronic pancreatitis and first-ESWL; stone diagnosis and first-ESWL; } \\
\text { steatorrhea initiation and first-ESWL; pseudocyst formation and first-ESWL; CBD stenosis and first-ESWL; pancreas surgery } \\
\text { and first-ESWL; } \\
\text { Symptom attacks (and age of each): SAP; first acute pancreatitis; last acute pancreatitis; first abdominal pain attack (without } \\
\text { amylase increase) } \\
\text { First chronic pain attack; times of acute pancreatitis attacks; acute pancreatitis frequency; latest acute pancreatitis attack in } \\
3 \text { months before ESWL }\end{array}$ \\
\hline Treatment history & $\begin{array}{l}\text { Previous ERCP; successful drainage with previous ERCP; previous EPT; previous pancreatic duct stent implantation; history of } \\
\text { complications after ERCP; pancreas surgery history; age at pancreas surgery }\end{array}$ \\
\hline Stone features & Single or multiple stone(s), radiolucent/opaque stone, stone(s) location \\
\hline Details of first-ESWL & $\begin{array}{l}\text { Age at ESWL; ESWL with pseudocyst existence; ESWL with pancreatic duct stent existence; ESWL with CBD stent existence; } \\
\text { single/multiple targeted stone(s); radiolucent/opaque targeted stone(s); location of targeted stone(s); position of patient; } \\
\text { shock wave frequency; pressure of water capsule }{ }^{3} \text {; shock wave energy level; anesthetic dose during ESWL; anesthetic dose } \\
\text { per body surface area; number of shocks for first-ESWL; X-ray exposure time; further ESWL(s) }\end{array}$ \\
\hline
\end{tabular}

CBD, common bile duct; ESWL, extracorporeal shock wave lithotripsy; SAP, severe acute pancreatitis; MPD, main pancreatic duct; HCP, heredity chronic pancreatitis; ERCP, endoscopic retrograde cholangiopancreatography; EPT, endoscopic papillotomy.

${ }^{1}$ Diagnosis standard of alcoholic chronic pancreatitis was used to present the alcohol consumption as a binary categorical factor.

2 Patients with first-degree relative(s) with chronic or recurrent acute pancreatitis were diagnosed as HCP.

${ }^{3}$ This measure indicates the distance between the shock wave head and targeted stone.

\section{Results}

$\nabla$

A total of 634 consecutive patients who underwent 1470 ESWL procedures were included in the study. The mean number of PESWL sessions and number of shock waves per patient were 2.3 sessions and 11640 shock waves, respectively. The general characteristics of patients are listed in Table 3. Complications occurred in 99 procedures ( Table 4). One procedure resulted in complications of moderate post-ESWL pancreatitis and mild bleeding (hematoma in the hepatic portal) and was classified as a moderate complication. A total of 16 procedures caused moderate-to-severe complications. No other rare complications were observed with the exception of pancreas fistula in one patient. One patient with hepatic subcapsular hematoma was treated with percutaneous hematoma drainage. Other patients suffering from complications recovered under close observation and conservative medical treatment. Overall, the P-ESWL complication rate was $6.7 \%$, and the prevalence of moderate-to-severe complications was $1.1 \%$ of the 1470 P-ESWL procedures.

For the first P-ESWL sessions, 62 patients (9.8\%) experienced complications ( Table 4). Post-ESWL pancreatitis was the most common complication, with an occurrence rate of $6.8 \%$ and accounting for $69.4 \%$ of complications.

\section{Risk factors for complication}

All of the potential risk factors were assessed by univariate analysis and 10 factors were significantly related to P-ESWL complications ( Table 5). These 10 factors were included in the binary logistic regression analysis. The results showed that five factors were independent predictors of P-ESWL complications. The independent predictors included protective factors such as male sex, diabetes, and steatorrhea as well as the risk factors of pancreas

\begin{tabular}{|lc|}
\hline Table 3 Patient characteristics in the study. \\
\end{tabular}

P-ESWL, pancreatic extracorporeal shock wave lithotripsy; ACP, alcoholic chronic pancreatitis; ICP, idiopathic chronic pancreatitis; CBD, common bile duct; ERCP, endoscopic retrograde cholangiopancreatography.

${ }^{1}$ Repeated abdominal pain attacks without a significant increase in serum amylase. 


\begin{tabular}{|c|c|c|c|c|}
\hline \multirow[t]{2}{*}{ Complication } & \multirow[t]{2}{*}{ Total (\% of total procedures) } & \multicolumn{3}{|c|}{ Severity of complication } \\
\hline & & Mild & moderate & severe \\
\hline \multicolumn{5}{|l|}{ All P-ESWLs $(n=1470)$} \\
\hline Overall complication & $99^{1}(6.7)$ & 84 & 13 & 3 \\
\hline Post-ESWL pancreatitis & $64(4.4)$ & 52 & 10 & 2 \\
\hline Infection & $20(1.4)$ & 19 & 0 & 1 \\
\hline Steinstrasse & $6(0.4)$ & 5 & 1 & 0 \\
\hline Perforation & $4(0.3)$ & 4 & 0 & 0 \\
\hline Bleeding & $5(0.3)$ & 4 & 1 & 0 \\
\hline Pancreatic fistula & $1(0.1)$ & 0 & 1 & 0 \\
\hline \multicolumn{5}{|c|}{ First P-ESWL session $(n=634)$} \\
\hline Overall complication & $62(9.8)$ & 51 & 10 & 1 \\
\hline Post-ESWL pancreatitis & $43(6.8)$ & 35 & 7 & 1 \\
\hline Infection & $12(1.9)$ & 11 & 0 & 1 \\
\hline Steinstrasse & $3(0.5)$ & 2 & 1 & 0 \\
\hline Perforation & $2(0.3)$ & 2 & 0 & 0 \\
\hline Bleeding & $2(0.3)$ & 1 & 1 & 0 \\
\hline
\end{tabular}

Table 4 Complication frequency and severity of extracorporeal shock wave lithotripsy.

P-ESWL, pancreatic extracorporeal shock wave lithotripsy.

${ }^{1}$ One procedure resulted in both moderate post-ESWL pancreatitis and mild bleeding (hematoma in the hepatic portal), which were classified as a moderate complication.

Table 5 Risk factors for the complications of first extracorporeal shock wave lithotripsy in univariate and multivariate analyses.

\begin{tabular}{|c|c|c|c|c|c|}
\hline Variate & $\begin{array}{l}\text { Cases with any } \\
\text { complications ( } n=62) \\
n(\%)\end{array}$ & $\begin{array}{l}\text { Control }^{1} \\
(n=572) \\
n(\%)\end{array}$ & $\begin{array}{l}\text { Univariate } \\
P \text { value }\end{array}$ & $\begin{array}{l}\text { Multivariate } P \\
\text { value }\end{array}$ & $\begin{array}{l}\text { Adjusted odds ratio } \\
(95 \% \mathrm{Cl})\end{array}$ \\
\hline \multicolumn{6}{|l|}{ Significant in the multivariate analysis } \\
\hline Sex (male) & $37(59.7)$ & $434(75.9)$ & 0.006 & 0.014 & $0.50(0.28,0.87)$ \\
\hline Diabetes & $9(14.5)$ & $168(29.4)$ & 0.013 & 0.034 & $0.45(0.21,0.94)$ \\
\hline Steatorrhea & $7(11.3)$ & $128(22.4)$ & 0.043 & 0.049 & $0.43(0.19,0.99)$ \\
\hline Pancreas divisum & $5(8.1)$ & $15(2.6)$ & 0.037 & 0.011 & $4.38(1.41,13.63)$ \\
\hline Time between diagnosis and ESWL & & & 0.049 & 0.048 & $1.28(1.00,1.64)$ \\
\hline $0-1$ year & $31(50.0)$ & $360(62.9)$ & & & \\
\hline $1-3$ years & $14(22.6)$ & $102(17.8)$ & & & \\
\hline $3-5$ years & $11(17.7)$ & $47(8.2)$ & & & \\
\hline$\geq 5$ years & $6(9.7)$ & $63(11.0)$ & & & \\
\hline \multicolumn{6}{|l|}{ Significant in the univariate analysis } \\
\hline Alcohol consumption & $14(22.6)$ & $221(38.6)$ & 0.013 & & \\
\hline Onset of symptoms & & & 0.069 & & \\
\hline Abdominal pain & $54(87.1)$ & $441(77.1)$ & & & \\
\hline Function insufficiency & $1(1.6)$ & $60(10.5)$ & & & \\
\hline Others & $7(11.3)$ & $71(12.4)$ & & & \\
\hline $\begin{array}{l}\text { Frequent attack of acute pancreatitis } \\
\text { ( } \geq 1 / \text { year) }\end{array}$ & $18(29.0)$ & $109(19.1)$ & 0.062 & & \\
\hline $\begin{array}{l}\text { P-ESWL procedure with pancreatic stent(s) } \\
\text { in situ }\end{array}$ & $5(8.1)$ & $94(16.4)$ & 0.085 & & \\
\hline $\begin{array}{l}\text { Shock wave frequency } \\
\text { ( } \geq 100 \text { shocks/minute) }\end{array}$ & $53(85.5)$ & $432(75.5)$ & 0.079 & & \\
\hline
\end{tabular}

P-ESWL, pancreatic extracorporeal shock wave lithotripsy; CI, confidence interval.

${ }^{1}$ Control group were patients without complications after the first P-ESWL session.

divisum and longer interval between diagnosis of chronic pancreatitis and P-ESWL.

\section{Risk factors for moderate-to-severe complication}

Only 11 patients suffered from moderate-to-severe complications after the first P-ESWL session. Logistic regression analysis involved four potential risk factors determined by univariate analysis. Male sex was identified as an independent protective factor associated with moderate-to-severe complications ( $\bullet$ Table 6).
Risk factors for post-ESWL pancreatitis

In the analysis of the risk factors for post-ESWL pancreatitis, the patients suffering from complications other than post-ESWL pancreatitis were excluded. Patients without P-ESWL complications were set as the control group. Among the included potential risk factors, 10 were significantly different between patients with and without post-ESWL pancreatitis. Logistic regression analysis results showed that four patient-related factors were independently associated with post-ESWL pancreatitis: male sex and steator- 
Table 6 Risk factors of moderate-to-severe complications of first extracorporeal shock wave lithotripsy in univariate and multivariate analyses.

\begin{tabular}{|c|c|c|c|c|c|}
\hline Variate & $\begin{array}{l}\text { Cases with } \\
\text { moderate-to-severe } \\
\text { complication } \\
(\mathrm{n}=11) \\
\mathrm{n}(\%)\end{array}$ & $\begin{array}{l}\text { Control }{ }^{1} \\
(n=623) \\
n(\%)\end{array}$ & $\begin{array}{l}\text { Univariate } \\
P \text { value }\end{array}$ & Multivariate $P$ value & $\begin{array}{l}\text { Adjusted odds ratio } \\
(95 \% \mathrm{Cl})\end{array}$ \\
\hline \multicolumn{6}{|c|}{ Significant in the multivariate analysis } \\
\hline Sex (male) & $4(36.4)$ & $467(75.0)$ & 0.008 & 0.009 & $0.19(0.05-0.66)$ \\
\hline \multicolumn{6}{|c|}{ Significant in the univariate analysis } \\
\hline Diabetes & $0(0.0)$ & $177(28.4)$ & 0.040 & & \\
\hline $\begin{array}{l}\text { Pseudocyst during chronic } \\
\text { pancreatitis course }\end{array}$ & $3(27.3)$ & $138(22.2)$ & 0.100 & & \\
\hline Alcohol consumption & $1(9.1)$ & $64(10.3)$ & 0.062 & & \\
\hline
\end{tabular}

$\mathrm{Cl}$, confidence interval.

${ }^{1}$ Control group were patients without moderate-to-severe complications after the first pancreatic extracorporeal shock wave lithotripsy session.

Table 7 Risk factors of post-extracorporeal shock wave lithotripsy (ESWL) pancreatitis of the first ESWL session in univariate and multivariate analyses.

\begin{tabular}{|c|c|c|c|c|c|}
\hline Variate & $\begin{array}{l}\text { Cases with first } \\
\text { P-ESWL post-ESWL } \\
\text { pancreatitis ( }=43 \text { ) } \\
n(\%)\end{array}$ & $\begin{array}{l}\text { Control } \\
(n=572)^{1} \\
n(\%)\end{array}$ & $\begin{array}{l}\text { Univariate } \\
P \text { value }\end{array}$ & $\begin{array}{l}\text { Multivariate } \\
P \text { value }\end{array}$ & $\begin{array}{l}\text { Adjusted odds ratio } \\
(95 \% \mathrm{Cl})\end{array}$ \\
\hline \multicolumn{6}{|l|}{ Significant in the multivariate analysis } \\
\hline Sex (male) & $22(51.2)$ & $434(75.9)$ & $<0.001$ & 0.001 & $0.32(0.17-0.62)$ \\
\hline Steatorrhea & $4(9.3)$ & $128(22.4)$ & 0.044 & 0.038 & $0.31(0.11-0.94)$ \\
\hline Pancreas divisum & $5(11.6)$ & $15(2.6)$ & 0.009 & 0.003 & $6.07(1.86-19.82)$ \\
\hline Frequent attack of acute pancreatitis ( $\geq 1$ /year) & $14(32.6)$ & $109(19.1)$ & 0.033 & 0.011 & $2.55(1.24-5.22)$ \\
\hline \multicolumn{6}{|l|}{ Significant in the univariate analysis } \\
\hline Diabetes & $7(16.3)$ & $167(29.2)$ & 0.069 & & \\
\hline CBD stenosis & $6(14.0)$ & $38(6.6)$ & 0.077 & & \\
\hline Alcohol consumption & $9(20.9)$ & $221(38.6)$ & 0.02 & & \\
\hline Single/multiple stones (multiple) & $41(95.4)$ & $489(85.5)$ & 0.074 & & \\
\hline Position (the $30^{\circ}$-right supine position) & $37(86.1)$ & $417(72.9)$ & 0.061 & & \\
\hline Shock wave frequency $\geq 100 /$ minute & $38(88.4)$ & $431(75.4)$ & 0.055 & & \\
\hline
\end{tabular}

CBD, common bile duct; P-ESWL, pancreatic extracorporeal shock wave lithotripsy; Cl, confidence interval.

${ }^{1}$ Control group were patients without complications after the first P-ESWL session (19 patients with complications other than post-ESWL pancreatitis were excluded from the control group).

rhea were protective factors, and pancreas divisum and frequent attacks of acute pancreatitis were risk factors $(\bullet$ Table 7$)$.

\section{Risk factors of TAE}

TAE after P-ESWL was not evaluated in the 154 ESWLs procedures (78 patients) performed before July 2011. In the 1316 procedures with TAE evaluation, 279 (21.2\%) showed TAE-positive results ( Table 8). Asymptomatic hyperamylasemia was observed in $15.5 \%$ of 1316 P-ESWLs. The occurrence rate of hematuria was $4.2 \%$.

In the first ESWL procedures, the number of patients with TAE was $142 / 514$ (27.6\%) ( Table 9). Patients suffering from both complications and TAE from the first P-ESWL session were not included in the analysis of TAE risk factors. The details of specific TAEs are presented in Table 8 . In all, 15 factors were significantly different between TAE and control groups in the univariate analysis. To avoid including overlapping variates in the multivariate analysis, only 11 of the 15 variates were included in the logistic analysis. Five protective factors (diabetes, steatorrhea, previous ERCP, needing further P-ESWL, multiple-location of targeted stones) and two risk factors (acute pancreatitis attack in 3
Table 8 Transient adverse events as frequency of the total extracorporeal shock wave lithotripsy sessions and the first session only.

\begin{tabular}{|llr|}
\hline TAE & $\mathbf{n}$ & \% \\
\hline All P-ESWL sessions $(\mathbf{n = 1 3 1 6})$ & & \\
\hline Overall TAE & $279\left(295^{1}\right)$ & 21.2 \\
\hline Asymptomatic hyperamylasemia & 204 & 15.5 \\
\hline Hematuria & 55 & 4.2 \\
\hline Acute gastrointestinal mucosal injury & 36 & 2.7 \\
\hline First P-ESWL session $(\mathbf{n}=\mathbf{5 1 4})$ & & \\
\hline Overall TAE & $142\left(152^{2}\right)$ & 27.6 \\
\hline Asymptomatic hyperamylasemia & 122 & 23.7 \\
\hline Hematuria & 20 & 3.9 \\
\hline Acute gastrointestinal mucosal injury & 10 & 2.0 \\
\hline
\end{tabular}

TAE, transient adverse event; P-ESWL, pancreatic extracorporeal shock wave lithotripsy.

${ }^{1}$ A total of 295 TAEs referred to 279 procedures.

${ }^{2} \mathrm{~A}$ total of 152 TAEs referred to 142 procedures in the 514 first P-ESWL session. 
Table 9 Risk factors of transient adverse events of the first pancreatic extracorporeal shock wave lithotripsy session in univariate and multivariate analyses.

\begin{tabular}{|c|c|c|c|c|c|}
\hline Variate & $\begin{array}{l}\text { Cases with first P- } \\
\text { ESWL TAE } \\
\left(n=133^{1}\right) \\
n(\%)\end{array}$ & $\begin{array}{l}\text { Control } \\
\left(n=372^{1}\right) \\
n(\%)\end{array}$ & $\begin{array}{l}\text { Univariate } \\
P \text { value }\end{array}$ & $\begin{array}{l}\text { Multivariate } \\
P \text { value }\end{array}$ & $\begin{array}{l}\text { Adjusted odds ratio } \\
(95 \% \mathrm{Cl})\end{array}$ \\
\hline \multicolumn{6}{|l|}{ Significant in the multivariate analysis } \\
\hline Diabetes & $24(18.1)$ & $134(36.0)$ & $<0.001$ & 0.030 & $0.56(0.33,0.95)$ \\
\hline Steatorrhea & $14(10.5)$ & $101(27.2)$ & $<0.001$ & 0.001 & $0.34(0.18,0.66)$ \\
\hline Attack of acute pancreatitis in 3 months & $55(41.4)$ & $75(20.2)$ & $<0.001$ & 0.001 & $2.24(1.42,3.54)$ \\
\hline Pseudocyst in chronic pancreatitis course & $22(16.5$ & $31(8.3)$ & 0.008 & 0.032 & $1.99(1.02,3.74)$ \\
\hline Previous ERCP & $55(41.4)$ & $185(49.7)$ & 0.097 & 0.004 & $0.52(0.33,0.81)$ \\
\hline Further P-ESWL(s) & $71(53.4)$ & $266(71.5)$ & $<0.001$ & $<0.001$ & $0.46(0.29,0.71)$ \\
\hline Multiple-location of targeted stones ${ }^{2}$ & $2(1.5)$ & $26(7.0)$ & 0.018 & 0.041 & $0.21(0.05,0.94)$ \\
\hline \multicolumn{6}{|l|}{ Significant in the univariate analysis } \\
\hline Initial symptom & & & 0.005 & & \\
\hline Abdominal pain & $116(87.2)$ & $276(74.2)$ & & & \\
\hline Functional insufficiency & $10(7.5)$ & $45(12.1)$ & & & \\
\hline Others & $7(5.3)$ & $51(13.7)$ & & & \\
\hline $\begin{array}{l}\text { Frequency of acute pancreatitis attacks }{ }^{3} \text {, median } \\
\text { (range) }\end{array}$ & $2(0-30)$ & $1(0-72)$ & $<0.001$ & & \\
\hline Frequent ( $\geq 1$ /year) & $39(29.3)$ & $51(13.7)$ & $<0.001$ & & \\
\hline \multicolumn{6}{|l|}{ Time between } \\
\hline Last acute attack and P-ESWL ${ }^{3}$, median (range) & $0.22(0.0-13.6)$ & $0.60(0.0-20.7)$ & 0.019 & & \\
\hline $\begin{array}{l}\text { Onset of chronic pancreatitis and P-ESWL } \\
\text { median (range) }\end{array}$ & $5.30(0.0-48.4)$ & $5.9(0.0-50.8)$ & 0.058 & & \\
\hline Time between onset and ESWL & & & 0.023 & & \\
\hline $0-1$ year & $30(22.6)$ & $55(14.8)$ & & & \\
\hline $1-3$ years & $24(18.1)$ & $49(13.2)$ & & & \\
\hline $3-5$ years & $12(9.0)$ & $62(16.7)$ & & & \\
\hline$\geq 5$ years & $67(50.4)$ & $206(55.4)$ & & & \\
\hline Location of pancreas stones & & & $<0.001$ & & \\
\hline Head alone (reference) & $108(81.2)$ & $253(68.0)$ & & & \\
\hline Body or both body and tail & $8(6.0)$ & $8(2.2)$ & & & \\
\hline Head and at least another part & $17(12.8)$ & $111(29.8)$ & & & \\
\hline Targeted pancreas stones location ${ }^{2}$ & & & 0.051 & & \\
\hline Head alone (reference) & $117(88.0)$ & $307(82.5)$ & & & \\
\hline Body or both body and tail & $6(4.5)$ & $9(2.4)$ & & & \\
\hline Head and at least another part & $2(1.5)$ & $22(5.9)$ & & & \\
\hline
\end{tabular}

P-ESWL, pancreatic extracorporeal shock wave lithotripsy; ERCP, endoscopic retrograde cholangiopancreatitis

${ }^{1}$ Data of first ESWL session transient adverse events (TAEs) for 67 patients subjected to P-ESWL before July 2011 were not collected; 62 patients with complications were excluded

from this analysis; thus, the total number of patients included in the analysis of first ESWL TAE was 505; among these patients, 133 suffered from TAE.

2 Targeted stones during first ESWL session of one patient could be multiple and distributed in different locations.

${ }^{3}$ To avoid overlapping effect, these variates were not included in the multivariate analysis.

months, pseudocyst in chronic pancreatitis course) were detected $(\bullet$ Table 9$)$.

\section{Complications of the second P-ESWL session}

Among the 634 patients undergoing ESWL, 409 were treated with more than one P-ESWL session. For the second P-ESWL session, complications were observed in 22 patients (5.4\%). Among these patients, three were classified as having moderate-to-severe complications. The complication rate for the second PESWL session was lower than that for the first session. Moreover, among the 22 patients, five patients had suffered from complications in the first session. Post-ESWL pancreatitis was the most repeated event. The association of adverse events from the first PESWL session and those from the second session was assessed - Table 10). Post-ESWL pancreatitis and asymptomatic hyperamylasemia after the first session were significantly associated with a higher risk of complications following the second P-ESWL session.

\section{Discussion}

Adverse events in urinary ESWL have been classified [21], and studies have focused on the risk factors of ESWL-related complications [22,23]. In P-ESWL, which has been clinically applied to the fragmentation of pancreatic stones since 1987, no specific studies on the complications of P-ESWL and related risk factors have been reported. In this prospective study, the adverse events of P-ESWL were described in detail in terms of complications and TAEs. Several risk factors were found. The overall complication and TAE rates were $6.7 \%$ and $21.2 \%$, respectively. Considering the first P-ESWL sessions, the complication and TAE rates were $9.8 \%$ and $27.6 \%$, respectively.

Diabetes and steatorrhea, which are caused by serious insufficient endocrine/exocrine pancreas functions, are protective factors for P-ESWL complications. The relatively lower complication rate may be attributed to the damage in the pancreas from chronic pancreatitis as shown in post-ERCP complications [24]. However, the results also showed that the intervals between the onset 
Table 10 Univariate analysis of first pancreatic extracorporeal shock wave lithotripsy (P-ESWL) adverse events for second P-ESWL complications ( $\mathrm{n}=409^{1}$ )

\begin{tabular}{|c|c|c|c|c|c|}
\hline & $\begin{array}{l}\text { Control }^{2} \\
(\mathrm{n}=387) \\
\mathrm{n}(\%)\end{array}$ & $\begin{array}{l}\text { Cases with second } \\
\text { P-ESWL complication } \\
(\mathrm{n}=22) \\
\mathrm{n}(\%)\end{array}$ & $P$ & $\begin{array}{l}\text { Cases with second P-ESWL } \\
\text { post-ESWL pancreatitis } \\
(n=14) \\
n(\%)\end{array}$ & $P$ \\
\hline First P-ESWL complication & $29(7.5)$ & $5(22.7)$ & 0.028 & $4(28.6)$ & 0.022 \\
\hline First P-ESWL post-ESWL pancreatitis & $18(4.7)$ & $4(18.2)$ & 0.023 & $4(28.6)$ & 0.005 \\
\hline First P-ESWLTAE & $68(17.6)$ & $7(31.8)$ & 0.076 & $7(50.0)$ & 0.002 \\
\hline First P-ESWL asymptomatic hyperamylasemia & $53(13.7)$ & $7(31.8)$ & 0.021 & $7(50.0)$ & $<0.001$ \\
\hline
\end{tabular}

P-ESWL, pancreatic extracorporeal shock wave lithotripsy; TAE, transient adverse event.

${ }^{1}$ Among 634 patients subjected to P-ESWL(s) treatment, 409 required further P-ESWL(s) after the first-ESWL sessions.

2 Patients free from any complications in the second P-ESWL acted as the control group in analyses for both second P-ESWL complication and second P-ESWL post-ESWL pancreatitis.

of chronic pancreatitis and P-ESWL, which directly affects the duration of chronic pancreatitis course, did not predict the risk of complications. This result can be attributed to the fact that the functional loss of the pancreas is not associated with the time course.

Pancreas divisum was detected as a risk factor for P-ESWL complications, specifically post-ESWL pancreatitis. The relatively narrower caliber of the accessory pancreatic duct and the minor papilla may expose patients with pancreas divisum to the risk of pancreatic juice outflow obstruction after P-ESWL.

Similar to ERCP complications, the female sex is a risk factor for PESWL complications. The underlying cause may be the dysfunction of the sphincter of Oddi, which is reported as a condition primarily affecting women and risk factor for post-ERCP pancreatitis [25]. Moreover, women may be more susceptible to an inflammatory response to pancreas damage [26]. In moderate-to-severe complications, female sex was also a risk factor in the current study. Frequent acute attacks during the chronic pancreatitis course suggested a high risk of post-ESWL pancreatitis. A high frequency of acute attacks may indicate that the patient is genetically susceptible to acute pancreatitis and has high enzymatic activity of the pancreas.

According to the treatment strategy, ERCP was only performed after P-ESWL, indicating that the presence of pancreatic duct stricture could only be evaluated after P-ESWL. The pancreatic duct morphology through ERCP after P-ESWL might differ from the structure before P-ESWL. Nevertheless, pancreatic duct stricture and previous treatments are important factors, and these had been considered as potential predictors of P-ESWL complications in this study. However, all of these factors, with the exception of P-ESWL with pancreatic stent in situ, showed $P$ values of $>0.10$ in univariate analyses and were therefore excluded as initial candidates for multivariate analysis. Pancreatic duct stricture and previous treatments may not be associated with PESWL complications.

No procedure-related factors independently increased the risk of complications. Shock wave frequency and the number of shock waves are important factors in the field of urinary ESWLs. Studies have found that a decrease in frequency ( 60 shocks per minute to 90 shocks per minute) is likely to increase the success rate of fragmentation and improve safety [27]. A high number of shock waves is likely to increase the risk of complications. For P-ESWL, the shock wave frequency and the number of shock waves did not affect the rates of complications and TAEs. In the current study, risk factor analyses were limited to the data of the first PESWL procedures, and the number of shock waves in a single PESWL session was limited to a maximum of 5000 shocks. Both of these factors may have contributed to the results, in which no procedure-related factors were found.

Asymptomatic hyperamylasemia and hematuria were common TAEs with respective incidence rates of $15.5 \%$ and $4.2 \%$. Hyperamylasemia after P-ESWL was not distinguished from pancreatitis in published studies [5,28]. Hematuria is the most common manifestation after urinary ESWL, and is caused by the shock wave energy delivered to the kidney, resulting in mild renal injury. For P-ESWL, this condition is seldom reported [12] because of lack of observation. The prevalence of acute gastrointestinal mucosal injury was $2.7 \%$ of P-ESWL procedures in the current study. A study of urinary ESWL has shown gastroduodenal erosions in $80 \%$ of patients who underwent pre- and post-ESWL endoscopies [29]. In the current study, overall incidence of asymptomatic hyperamylasemia, hematuria, and acute gastrointestinal injury was $21.2 \%$ (27.6\% for first ESWL session).

In the second ESWL session in the current study, complications were observed in only $5.4 \%(22 / 409)$ of the patients, which is lower than the rate from the first session. The relatively lower number of complications in the second session may have resulted from the decrease in the stone volume in the pancreas and the partial obstruction release in the pancreatic duct. The pancreas can also adapt to shock waves in subsequent ESWL sessions and this may have contributed to the lower risk. Patient-related factors, which are important in P-ESWL complications, were consistent between the first and second P-ESWL sessions. Thus, patients who experienced complications during the first P-ESWL session were prone to complications during subsequent sessions. This study has several limitations. To our knowledge, this study is the first to determine the risk factors for P-ESWL complications; however, there may be unknown factors affecting P-ESWL complication rates. Second, the classification of P-ESWL complications established in the study has not been approved by global counterparts; as such, the proposed classification should be investigated further. Third, the absolute number of moderate-tosevere complications was small $(11 / 634,1.7 \%)$, and the analysis of risk factors of moderate-to-severe events may therefore present biased results, despite the large population considered in the study.

In conclusion, the common complications of P-ESWL included post-ESWL pancreatitis, bleeding, infection, steintrasse, and perforation. Patient-related factors, including female sex, absence of diabetes, absence of steatorrhea, pancreas divisum, and longer interval since diagnosis of chronic pancreatitis, were risk factors for P-ESWL complications. The safety of a previous P-ESWL session may be a good predictor of the risk in subsequent P-ESWL sessions. The results from this study could help to improve the safety of P-ESWL. 
Competing interests: None.

\section{Acknowledgment \\ $\nabla$}

This study was supported by the National Natural Science Foundation of China (Grant Nos. 81270541 [Z.L.] and 81100316 [L.H. H.]), Shanghai Chenguang Program (Grant No.12CG40 [H.L.H.]), and Shanghai Rising-Star Program (Grant No.13QA1404600 [Z. L.]).

\section{References}

1 Kozarek RA, Ball TJ, Patterson DJ. Endoscopic approach to pancreatic duct calculi and obstructive pancreatitis. Am J Gastroenterol 1992; 87: $600-603$

2 Seven G, Schreiner MA, Ross AS et al. Long-term outcomes associated with pancreatic extracorporeal shock wave lithotripsy for chronic calcific pancreatitis. Gastrointest Endosc 2012; 75: 997 1004.e1001

3 Dumonceau JM, Costamagna G, Tringali $A$ et al. Treatment for painful calcified chronic pancreatitis: extracorporeal shock wave lithotripsy versus endoscopic treatment: a randomised controlled trial. Gut 2007; 56: 545-552

$4 \mathrm{Hu}$ LH, Liao Z, Li ZS. Spontaneous clearance of pancreatic stones. Clin Gastroenterol Hepatol 2013; 11: e9-e10

5 Sauerbruch T, Holl J, Sackmann $M$ et al. Extracorporeal lithotripsy of pancreatic stones in patients with chronic pancreatitis and pain: a prospective follow up study. Gut 1992; 33: 969-972

6 Ong WC, Tandan M, Reddy V et al. Multiple main pancreatic duct stones in tropical pancreatitis: safe clearance with extracorporeal shockwave lithotripsy. J Gastroenterol Hepatol 2006; 21: 1514-1518

7 Tandan M, Reddy DN, Santosh D et al. Extracorporeal shock wave lithotripsy and endotherapy for pancreatic calculi - a large single center experience. Indian J Gastroenterol 2010; 29: 143 - 148

$8 \mathrm{Hu}$ LH, Liao Z, Li ZS. Rolling in the deep: a quaint sphere rolling in the deep pancreatic duct. Gastroenterology 2013; 145: e7-e8

9 Guda NM, Partington S, Freeman ML. Extracorporeal shock wave lithotripsy in the management of chronic calcific pancreatitis: a meta-analysis. JOP 2005; 6: 6-12

10 Bhasin DK, Rana SS. Extracorporeal shock wave lithotripsy (ESWL) for large pancreatic stones: are these shocks worthwhile? Indian J Gastroenterol 2010; 29: 133-136

11 Kozarek RA, Brandabur JJ, Ball TJ et al. Clinical outcomes in patients who undergo extracorporeal shock wave lithotripsy for chronic calcific pancreatitis. Gastrointest Endosc 2002; 56: 496-500

12 Inui K, Tazuma S, Yamaguchi $T$ et al. Treatment of pancreatic stones with extracorporeal shock wave lithotripsy - results of a multicenter survey. Pancreas 2005; 30: $26-30$
13 Plaisier PW, den HoedPT. Splenic abscess after lithotripsy of pancreatic duct stones. Dig Surg 2001; 18: 231-232

14 Leifsson BG, Borgstrom A, Ahlgren G. Splenic rupture following ESWL for a pancreatic duct calculus. Dig Surg 2001; 18: 229-230

15 Hirata $N$, Kushida Y, Ohguri $T$ et al. Hepatic subcapsular hematoma after extracorporeal shock wave lithotripsy (ESWL) for pancreatic stones. J Gastroenterol 1999; 34: 713-716

16 Nakagawa $Y$, Abe T, Uchida $M$ et al. Hemorrhagic pseudoaneurysm in a pancreatic pseudocyst after extracorporeal shock wave lithotripsy for pancreatolithiasis. Endoscopy 2011; 43: E310-311

17 Tandon RK, Sato N, Garg PK. Chronic pancreatitis: Asia-Pacific consensus report. J Gastroenterol Hepatol 2002; 17: 508 -518

$18 \mathrm{Hu} \mathrm{LH}$, Liu MH, Liao Z et al. Steinstrasse formation after extracorporeal shock wave lithotripsy for pancreatic stones. Am J Gastroenterol 2012; 107: $1762-1764$

19 Cotton PB, Lehman G, Vennes J et al. Endoscopic sphincterotomy complications and their management: an attempt at consensus. Gastrointest Endosc 1991; 37: 383-393

20 Dumonceau JM, Delhaye M, Tringali A et al. Endoscopic treatment of chronic pancreatitis: European Society of Gastrointestinal Endoscopy (ESGE) Clinical Guideline. Endoscopy 2012; 44: 784-800

21 Smith LH, Drach G, Hall P et al. National High Blood Pressure Education Program (NHBPEP) review paper on complications of shock wave lithotripsy for urinary calculi. Am J Med 1991; 91: 635-641

22 Lee HY, Yang YH, Shen JT et al. Risk factors survey for extracorporeal shockwave lithotripsy-induced renal hematoma. J Endourol 2013; 27: $763-767$

23 Madbouly K, Sheir KZ, Elsobky E et al. Risk factors for the formation of a Steinstrasse after extracorporeal shock wave lithotripsy: a statistical model. J Urol 2002; 167: 1239-1242

24 Cotton PB, Garrow DA, Gallagher J et al. Risk factors for complications after ERCP: a multivariate analysis of 11,497 procedures over 12 years. Gastrointest Endosc 2009; 70: 80-88

25 Freeman ML, DiSario JA, Nelson DB et al. Risk factors for post-ERCP pancreatitis: a prospective, multicenter study. Gastrointest Endosc 2001; 54: $425-434$

26 Wang P, Li ZS, Liu F et al. Risk factors for ERCP-related complications: a prospective multicenter study. Am J Gastroenterol 2009; 104: 31 - 40

$27 \mathrm{Li}$, Lin T, Zhang C et al. Optimal frequency of shock wave lithotripsy in urolithiasis treatment: a systematic review and meta-analysis of randomized controlled trials. J Urol 2013; 190: 1260-1267

28 Ohara $H$, Hoshino $M$, Hayakawa $T$ et al. Single application extracorporeal shock wave lithotripsy is the first choice for patients with pancreatic duct stones. Am J Gastroenterol 1996; 91: 1388 -1394

29 Al KarawiMA, Mohamed AR, el-Etaibi KE et al. Extracorporeal shockwave lithotripsy (ESWL)-induced erosions in upper gastrointestinal tract. Prospective study in 40 patients. Urology 1987; 30: 224-227 